\title{
A transcriptomic investigation of handicap models in sexual selection
}

\author{
Marius A. Wenzel ${ }^{1 *}$, Lucy M.I. Webster ${ }^{2}$, Steve Paterson ${ }^{3}$, \\ François Mougeot ${ }^{4}$, Jesus Martinez-Padilla ${ }^{5}$ and Stuart B. Piertney ${ }^{1}$ \\ $08 / 10 / 2012$
}

${ }^{1}$ Institute of Biological and Environmental

Sciences, University of Aberdeen, Zoology

Building, Tillydrone Avenue, Aberdeen AB24 2TZ, UK

2 Science and Advice for Scottish Agriculture, Roddinglaw Road, Edinburgh EH12 9FJ

${ }^{3}$ Institute of Integrative Biology, University of Liverpool, Liverpool L69 7ZB, UK

4 Estación Experimental de Zonas Áridas (CSIC), Carretera de Sacramento s/n, La Cañada de San Urbano, 04120 Almería, Spain; Instituto de Investigaciones en Recursos Cinegéticos (IREC-CSIC), Ronda de Toledo s/n, 13005, Ciudad Real, Spain

${ }^{5}$ Department of Evolutionary Ecology, National Museum of Natural History (MNCN-CSIC), c/ José Gutierrez Abascal 2, 28006 Madrid, Spain

* corresponding author. email address:

m.wenzel@abdn.ac.uk. Phone number: +44 1224 272395

Running title: Zahavian handicaps and transcriptomics

Keywords: sexual selection; immunocompetence handicap hypothesis; ICHH; oxidative stress handicap hypothesis; OSHH; transcriptomics

Total word count: 4,429 (Introduction: 1,261; Materials \& Methods: 536; Results: 555; Discussion: 2,077)

Cited references: 98

Figures: 2

Tables: 3

Supplementary materials: Tables S1-S4
Abstract

Handicap models link the evolution of secondary sexual ornaments to physiological costs and thus provide a mechanistic explanation for signal honesty in sexual selection. Two commonly invoked models, the immunocompetence handicap hypothesis $(\mathrm{ICHH})$ and the oxidative stress handicap hypothesis $(\mathrm{OSHH})$, involve suppression of immunocompetence $(\mathrm{ICHH})$ or increase of oxidative stress (OSHH) by testosterone, but empirical evidence for both models is controversial and based on assays of morphology and physiology. Here we investigated these two models on the gene expression level using microarrays to quantify the transcriptomic response of red grouse (Lagopus lagopus scoticus) to experimental manipulation of testosterone and parasite levels, and then examined whether the predicted effects of testosterone were observed. We used a GENEONTOLOGY (GO) framework to identify genes related to immune function and response to reactive oxygen species (ROS) and examined how transcription levels changed under experimentally increased testosterone levels in birds with parasites absent, natural chronic infection or experimental infection. Although some genes were significantly differentially regulated when parasites were present, more than $93 \%$ of identified immune genes and more than $95 \%$ of ROS response genes did not significantly respond to increased testosterone levels in all parasite treatment groups, providing little support for the ICHH and OSHH. More genes responded to testosterone in the presence rather than absence of parasites, suggesting that handicap mechanisms may be context dependent and more 
pronounced in the presence of adverse environmental conditions. These findings illustrate the utility of transcriptomics to investigating handicap models, suggest that the ICHH and OSHH do not underlie the handicap mechanism, and indicate that novel emerging models involving different mediators and physiological pathways should be examined.

\section{Introduction}

One prominent theme in sexual selection research is to elucidate the evolution of extravagant secondary sexual ornaments in males and to elucidate the mechanisms that maintain signal honesty (Andersson, 1994). Male ornaments are thought to act as quality signals to females during courtship to obtain the best mate and "good genes" for their offspring (Andersson, 1982, 1994). Zahavi's handicap principle (Zahavi, 1975) suggests that in order to be reliable indicators of male quality, sexually selected ornaments must be costly to maintain and therefore incur a fitness cost (a "handicap") that cheater males cannot afford to pay. Such a system would be evolutionarily stable (Maynard Smith, 1974) and ensure that ornaments are honest quality indicators (Grafen, 1990).

Various models have been proposed to explain the link between male quality and honest display of ornaments (Folstad and Karter, 1992; Møller and Saino, 1994; Olson and Owens, 1998; von Schantz et al, 1999; Blount et al, 2003; Alonso-Alvarez et al, 2007; Hill, 2011). One classic, still commonly invoked model is the immunocompetence handicap hypothesis (ICHH) by Folstad and Karter (1992). It proposes a trade-off between ornament intensity and immunocompetence (defined as the ability to mount an immune response upon exposure to an antigen) that is mediated by testosterone as both an enhancer of secondary sexual traits and a suppressor of immune function, primarily reflected in increased susceptibility to parasites (Hamilton and Zuk, 1982). Therefore, extravagant ornaments advertise a high quality immune system in males that are able to afford the immunosuppressive effect of testosterone.

Empirical studies have found evidence for a positive correlation between ornament intensity and im- munocompetence (e.g. Møller et al, 1998, 1999; Peters et al, 2004; Andersson et al, 2006; Mougeot, 2008) and a negative correlation with parasite load (e.g. Møller et al, 1999; Moore and Wilson, 2002; Hill and Farmer, 2005; Ottová et al, 2005). However, these correlations are not always supported (e.g. Hasselquist et al, 1999; Mougeot and Redpath, 2004; Kurtz, 2007) and indeed have been shown to be reversed in some cases (Roberts et al, 2004). As a means to testing the predictions of the $\mathrm{ICHH}$, parasite loads and testosterone levels have been manipulated in a broad range of study systems. Reviews and meta-analyses support that experimental parasite challenges decrease testosterone levels (Boonekamp et al, 2008) and ornament intensity (Møller et al, 1999). Various recent studies also support the predicted effects of increased testosterone levels, i.e. enhanced ornaments (e.g. Mougeot et al, 2004; Deviche and Cortez, 2005; Kurtz et al, 2007; Roberts et al, 2009b), increased parasite load (e.g. Mougeot et al, 2006; Seivwright et al, 2005; Deviche and Parris, 2006; Cox and John-Alder, 2007) and decreased immunocompetence (e.g. Mougeot et al, 2004; Oppliger et al, 2004; Deviche and Cortez, 2005; Kurtz et al, 2007; Edler et al, 2011; Gil and Culver, 2011). However, support for the latter is also frequently absent (e.g. Buchanan et al, 2003; Mougeot and Redpath, 2004; Oppliger et al, 2004; Ros et al, 2006; Alonso-Alvarez et al, 2009; Casagrande and Groothuis, 2011; Fuxjager et al, 2011; Ezenwa et al, 2012), and overall support for the ICHH is equivocal at best (Roberts et al, 2004).

Given this mixed support, alternative models have been suggested. One common alternative is the oxidative stress handicap hypothesis (OSHH), which extends the ICHH beyond the immune system to include the antioxidant machinery. Specifically, it posits that the trade-off that ensures honest signalling predominantly involves resistance to oxidative stress rather than solely immunocompetence (von Schantz et al, 1999; Alonso-Alvarez et al, 2007). As in the ICHH, the underlying mechanism is testosterone dependent: Testosterone increases the metabolic rate (Buchanan et al, 2001; Oppliger et al, 2004; Alonso-Alvarez et al, 2007) and may consequently increase the production of reactive oxygen species (ROS) that may cause tissue 
damage or compromise an immune system response (Alonso-Alvarez et al, 2007). However, it may also simultaneously enhance the availability of antioxidant carotenoids, which may be either allocated to compensate for an excess in ROS production or deposited into carotenoid-dependent ornaments (Blas et al, 2006; McGraw et al, 2006). Therefore, only males with high-quality antioxidant machinery can afford the increased ROS production induced by high testosterone levels and still divert available antioxidant carotenoids into ornaments.

Correlative studies have focussed on the relationship between ornament intensity and oxidative balance, rather than covariance with testosterone levels. Ornament intensity has been shown to predict oxidative DNA damage (Freeman-Gallant et al, 2011) and resistance to oxidative stress during an immune challenge (Pérez-Rodríguez et al, 2010). Experimental tests of the OSHH have been positive at large: increased testosterone levels increase oxidative stress (e.g. Alonso-Alvarez et al, 2007; Kurtz et al, 2007; Mougeot et al, 2009) but also antioxidant defences (e.g. Blas et al, 2006; McGraw et al, 2006; Mougeot et al, 2009) including carotenoids (e.g. Alonso-Alvarez et al, 2008; Martinez-Padilla et al, 2010). Manipulated parasite loads influence carotenoid and oxidative balance (e.g. MartinezPadilla et al, 2007; Mougeot et al, 2007, 2009, 2010a), but there are inconsistent interactions between testosterone and parasites on ornament intensity across populations, suggesting a role of environmental context (Martinez-Padilla et al, 2010). The OSHH might be a viable mechanism, but its relevancy for carotenoid-based ornaments depends on the assumptions of a testosterone-induced increase in the bioavailability of carotenoids (Blas et al, 2006) as well as a possible antioxidant function of carotenoids, but the latter is controversial (Costantini and Møller, 2008; Martínez et al, 2009; Vinkler and Albrecht, 2010).

All previous studies that have tested handicap models have used manipulations of hormone levels or parasite loads to capture subsequent morphological or physiological phenotype changes (Møller et al, 1999; Roberts et al, 2004). Examining morphology or physiology alone disregards the complex interactions of gene products and physiological pathways in different tissues that underpin phenotype expression (Casagrande and Groothuis, 2011; Ezenwa et al, 2012). Here we provide an alternative, more fundamental approach based on the transcriptomic phenotype rather than the physiological phenotype. We use microarrays to quantify the effect of experimentally increased testosterone levels on transcription levels of genes involved in immune response and ROS defence. The resulting patterns of up- and down-regulation of these genes in different tissues can then be used to assess whether the transcriptomic response conforms to the expectations of the ICHH or OSHH. Gene transcription is the initial response to environmental stimuli and can therefore be argued to represent a crucial stage in the generation of phenotypic variation. In spite of confounding regulation of gene expression downstream of gene transcription (Brockmann et al, 2007), transcriptome profiling has been shown to be a useful approach to characterising the physiological response to experimental treatments and to identifying candidate genes (e.g. Pemberton et al, 2011; Thompson et al, 2011; Debes et al, 2012; Matzkin, 2012).

Our focal study system is the red grouse (Lagopus lagopus scoticus Latham) and its main gastro-intestinal nematode parasite Trichostrongylus tenuis Mehlis. This parasite exhibits a direct life cycle; infective larvae are ingested with heather shoots and reside in the caecal mucosa where adult worms cause marked damage, resulting in weight loss, poor overall condition and potentially compromised survival and lowered fecundity (Watson et al, 1987; Hudson et al, 1992; Delahay et al, 1995). Prevalence of infection in grouse populations is greater than $90 \%$ (Wilson, 1983) and although grouse mount an immune response they cannot acquire immunity and thus bear chronic worm burdens for life (Shaw and Moss, 1989). The grousenematode system has previously been used to test the ICCH and OSHH involving morphological and physiological assays. Seivwright et al (2005) and Mougeot et al (2006) found that male grouse implanted with testosterone retained a higher parasite load after a standardised parasite challenge than control grouse. The implanted grouse also developed larger ornaments than control grouse and 
therefore supported both assumptions of the ICCH (Mougeot et al, 2006). More recently, a factorial field experiment involving experimentally manipulated testosterone levels and parasite loads was carried out to examine the interactions of testosterone and parasites on ornament intensity and oxidative balance (Mougeot et al, 2009, 2010a; MartinezPadilla et al, 2010). Increased testosterone levels enhanced ornaments and increased oxidative damage as well as circulating antioxidants (Mougeot et al, 2009). Removing parasites also enhanced ornaments, and increased parasite loads and testosterone levels together increased oxidative damage, overall suggesting an oxidative stress handicap in agreement with the OSHH (Mougeot et al, 2009, 2010a).

Based on the same factorial field experiment presented in Mougeot et al (2009), Webster et al (2011b) conducted a microarray experiment to characterise the interactive effects of parasite loads and testosterone levels on the caecum transcriptome. By comparing transcription levels of genes across treatment contrasts with different parasite loads and testosterone levels, they identified a set of genes that were up-regulated when parasites were present and subsequently down-regulated when testosterone levels were increased. Here, we use the same raw microarray data that were generated by Webster et al (2011b), but employ a conceptually different analytical approach on a different set of data. We a priori target genes related to immune system function and response to ROS production, and then examine transcription changes of these genes in caecum, spleen and liver of testosterone-treated grouse compared to control grouse across three parasite load treatments.

Under the ICHH, increased testosterone levels are expected to compromise the immune system, identifiable from changes in the underlying transcriptomic response. This can be mediated either directly through down-regulation of immune genes or up-regulation of genes that negatively regulate components of the immune system or compensate for down-regulated components elsewhere (Schmid-Hempel, 2003). We therefore hypothesise that immune genes become significantly up- or down-regulated in grouse with experimentally in- creased testosterone levels compared to grouse with natural levels. Similarly, central to the OSHH, increased testosterone levels are expected to increase ROS production and a concomitant defence response, i.e. antioxidant mobilisiation, to combat oxidative stress. In consequence, genes involved in ROS response, particularly in mobilising antioxidants, should become up-regulated. Alternatively, genes that negatively regulate antioxidant mobilisation may become down-regulated. We therefore hypothesise that ROS response genes become significantly up- or down-regulated in testosteronetreated grouse compared to untreated grouse. An overall lack of differential transcriptomic response between testosterone-treated grouse and control grouse in relevant genes would be inconsistent with the respective handicap models on the transcriptomic level.

\section{Materials and Methods}

\section{Field experiment and microarray as- says}

Details of the field experiment and microarray assays are described in Mougeot et al (2009) and Webster et al (2011b). Briefly, a factorial field experiment involving manipulation of testosterone levels and parasite loads in 40 male grouse was carried out in Edinglassie (Scotland) and Catterick (England) moors in autumn 2006. The birds were implanted with silastic tubes containing either testosterone proprionate (treatment $\mathrm{T}$ ) or saline (treatment I), and were either administered with the anthelmintic levamisole hydrochloride (treatment A), approximately 5,000 L3 $\mathrm{T}$. tenuis larvae following anthelmintic treatment (treatment $\mathrm{P}$ ) or not manipulated for parasite load at all (treatment $\mathrm{N}$ ). The treatments were shown to be effective for the duration of the experiment (Mougeot et al, 2009; Webster et al, 2011b).

Tissue samples were taken 3-4 weeks after experimental treatment and RNA was extracted for gene transcription analysis (Webster et al, 2011b). A bespoke grouse microarray was constructed from 9,600 clones, representing 5,925 unique sequence transcripts (contigs), obtained by standard cDNA 
libraries and suppressive subtractive hybridisation (SSH) from grouse with high versus low parasite loads (Webster et al, 2011a). All possible combinations (hereafter referred to as contrasts) of the six treatment groups were assayed on microarrays in a loop design, using RNA extracts from 27 birds in total (Webster et al, 2011b).

\section{Study design and data analysis}

In order to examine the assumptions of the ICHH and OSHH we first identified those contigs on the microarray that were involved in immune system function or ROS response before we analysed microarray data. We achieved this by interrogating all contig clone sequences against protein databases to identify gene products and then retrieving GENEONTOLOGY (GO) annotations (The Gene Ontology Consortium, 2000) to characterise each gene product in terms of biological process, molecular function and cellular component. We performed all database interrogations in December 2011 using the BLAST2GO framework (Conesa et al, 2005; Conesa and Götz, 2008). Contrary to the original annotation strategy by Webster et al (2011b), we employed a hierarchical search strategy. Firstly, all contigs were queried against the SWISSPROT database, using the NCBI Basic Local Alignment Search Tool (BLAST; http://www.ncbi.nlm.nih.gov/blast/Blast.cgi)

with an E-10 cut-off. Then, those contigs without a BLAST result were queried against the CHICKEN GENBANK PRotein database (gp/9031.10804// gga_genbank_prot), and subsequent failures were finally queried against the ZEBRAFINCH GENBANK PROTEIN database (gp/59729.12898// tg_genbank_prot). Each identified gene product was mapped and annotated (E-10 cut-off) for GO identifiers, and GO annotations were augmented by querying the ANNEx database (Myhre et al, 2006). GO annotations were then screened for GO:0002376 immune system process (GO level 2), GO:0006979 response to oxidative stress (GO level 4) and GO:0016209 antioxidant activity (GO level 2), including parent terms in all cases. The GO term response to oxidative stress covers gene products involved in all physiological processes that respond to exposure to ROS, whereas antioxidant activity covers antioxidant enzymes, e.g. superoxide dismutase, catalase and peroxidase.

This strategy identified 326 contigs in total. In order to investigate the transcriptomic response of these contigs to testosterone, we retrieved microarray data from the treatment contrasts TA vs. IA (number of grouse $n=4,3)$, TN vs. IN $(n=4,3)$ and TP vs. IP $(n=7,6)$. These contrasts represent the transcriptomic response to increased testosterone levels $\mathrm{T}$ (versus natural levels I) under anthelmintic treatment $\mathrm{A}$, natural chronic parasite infection $\mathrm{N}$ and parasite challenge $\mathrm{P}$, respectively. For each contig and contrast, we retrieved the relative difference in transcriptomic response between treatments (fold change) and the associated p-value for the null-hypothesis of no differential response (see Webster et al (2011b) for technical details). As a means to correct for false rejections of the null-hypothesis among these 326 contigs, we adjusted the $p$-value of each contig to account for the false discovery rate FDR (Benjamini and Hochberg, 1995) using the R package fdrtool (Strimmer, 2008). This package calculates falsediscovery-rate adjusted $p$-values ( $=q$-values) using a method that keeps the false non-discovery rate minimal (Strimmer, 2008). We performed FDRcorrection for each contrast separately and used the $p$-value distribution of the 326 identified contigs only rather than all contigs on the microarray. Contigs were identified as significantly differentially regulated when $q<0.05$.

\section{Results}

Of 5,925 unique DNA contigs on the microarray $1,864(31.5 \%)$ yielded a BLAST hit after cumulative interrogation of three protein databases, and of these 1,781 were successfully GO annotated (Table 1). Of these, 282 contigs were annotated with GO:0002376 immune system process (hereafter: immune genes) and 65 with either GO:0006979 response to oxidative stress (64 contigs) or GO:0016209 antioxidant activity (13 contigs) (hereafter: ROS response genes). A number of contigs were annotated with both immune system and ROS response categories, resulting in 326 identified 
contigs in total. The top BLAST hit descriptions for all identified contigs are presented in Tables S1 and S2. The set of immune genes covered various prominent constituents of the immune system (e.g. complement system, T-cell surface complexes, immunoglobulins and ubiquitin/proteasome-related complexes), whereas the set of ROS response genes covered a range of prominent antioxidant enzymes (e.g. catalase, superoxide dismutase, glutathione Stransferase, peroxiredoxins and glutaredoxins).

The effect of testosterone treatment on transcription regulation of these focal genes was weak overall. There was no significant effect at all in liver tissue, as the distribution of p-values was nearuniform across $[0 ; 1]$ in all contrasts, resulting in FDR-corrected $p$-values of $q \gg 0.05$ for all contigs. This was also the case in spleen tissue, apart from the TN vs. IN contrast in which three immune genes were significantly differentially regulated (Table 2). In comparison, gene transcription in caecum tissue was much more strongly affected. The changes in caecum gene transcription in each contrast are illustrated as volcano plots that plot $\log _{2}$ fold changes (measure of biological significance) against $-\log _{10} q$ (measure of statistical significance) (Figure 1). Four immune genes were significantly down-regulated in grouse with natural chronic parasite infection (TN vs. IN), whereas 17 were significantly down-regulated and three were significantly up-regulated in grouse with a parasite challenge (TP vs. IP) (Table 2). These contigs represent some prominent immune-system components, such as immunoglobulin chains, cellsurface proteins and complement factors, but also compounds involved in cell proliferation and motility, e.g. myosin, gelsolin and coronin (Table S3). A single ROS response gene (actin) was significantly up-regulated in the TN vs. IN contrast, whereas four ROS response genes were significantly down-regulated in the TP vs. IP contrast, none of which were prominent antioxidant enzymes (Table S4). No significantly differentially regulated immune genes and ROS response genes were found in grouse treated with an anthelmintic (TA vs. IA contrast).

The overall transcriptomic response to testosterone in caecum, extended beyond the focal im- mune and ROS response genes, was highly functionally varied in the three treatment contrasts under examination. A number of genes were significantly up- or down-regulated in each contrast (Fig. 1, Table 3) and the GO terms of these contigs covered a large number of categories in all ontologies. To illustrate the category range included, the most frequent level-2 and level-3 GO terms for the biological process ontology in all three treatment contrasts are presented in Fig. 2.

\section{Discussion}

We here provide a novel perspective to investigating handicap models in sexual selection by studying the transcriptome rather than the physiological phenotype. Specifically, we studied the transcriptomic response of red grouse to testosterone in three key tissues in order to investigate the main assumptions of the immunocompetence handicap hypothesis (ICHH) and oxidative stress handicap hypothesis (OSHH). We hypothesised that immune genes (ICHH) or genes involved in response to ROS (OSHH) become significantly up- or down-regulated in grouse treated with testosterone implants compared to control grouse. Only a small proportion of identified genes were significantly differentially regulated, with inconsistencies across tissues and parasite treatment groups. The OSHH results in particular are somewhat at odds with the physiological response to testosterone of the same birds, which was previously reported to support the OSHH (Mougeot et al, 2009). We discuss observed discrepancies between the transcriptomic and physiological phenotype and highlight potential pitfalls in the transcriptomic approach.

\section{Transcriptomic evidence for the ICHH and OSHH}

The main assumption of the ICHH is that testosterone simultaneously acts as an enhancer of male secondary traits, such as epigamic ornaments, and a suppressor of immunocompetence (Folstad and Karter, 1992). In red grouse, experimentally increased testosterone levels have been shown to enhance ornaments (Mougeot et al, 2004, 2009), 
increase parasite load (Seivwright et al, 2005; Mougeot et al, 2006) and decrease T-cell mediated immunity and overall condition (Mougeot et al, 2004). Given these findings, some transcriptomic evidence of a compromised immune system would be expected in testosterone-treated grouse, either directly through down-regulation of immune genes or up-regulation of genes that negatively regulate components of the immune system or compensate for down-regulated components (SchmidHempel, 2003). The volcano plots for immune genes in caecum tissue were overall asymmetrical with some bias towards (non-significant) downregulation. Most of the significantly differentially regulated immune genes were indeed downregulated, but the heavy-chain component of ferritin (also up-regulated in spleen) and the coxsackievirus and adenovirus receptor were up-regulated by testosterone in grouse with parasites present. Both of these proteins may have immunosuppressive properties (Carson and Chapman, 2001; Gray et al, 2001), so up-regulation by testosterone is fully compatible with the expectations. In conclusion, the transcriptomic response in caecum tissue of grouse with a parasite challenge may provide transcriptomic evidence for an immunosuppressive function of testosterone according to the ICHH. However, the absence of a transcriptomic response in liver and (in most cases) spleen tissue, the weak response in grouse with natural parasite loads and the lack of response in grouse treated with an anthelmintic weaken the evidence and are grounds for caution.

We further examined the main assumption of the OSHH that increased testosterone levels increase ROS production and consequently enhance the physiological response to ROS (Alonso-Alvarez et al, 2007). ROS production is expected to result in mobilisation of innate antioxidant defences in an attempt to regain a positive oxidative balance (Finkel and Holbrook, 2000), even if this cannot be attained due to a low-quality oxidation defence system. Testosterone-treated grouse have been shown to experience an increased total antioxidant status (TAS) and a concomitant increase in oxidative damage, suggesting that a testosteroneinduced oxidative stress handicap might be oper- ating (Mougeot et al, 2009). Therefore, an upregulation of ROS response genes (i.e. antioxidants) or a down-regulation of genes that negatively regulate antioxidant mobilisation would be expected in testosterone-treated grouse. However, none of the identified antioxidant genes were significantly differentially regulated in any contrast. Instead, a component of the cytoskeleton (actin) was significantly up-regulated in grouse with natural parasite levels, and four genes that do not possess anti-oxidant properties were significantly downregulated in grouse with a parasite challenge. The upregulation of actin may indicate a compensatory response to oxidative damage to the cytoskeleton (Farah et al, 2011), but these results provide no evidence for the OSHH under our initial hypothesis that anti-oxidants become upregulated.

A possible explanation for the observed lack of enhanced ROS response may be that there was no increased ROS production and therefore no concomitant ROS response, which would be inconsistent with the main assumption of the $\mathrm{OSHH}$ and contradict a presumed key metabolic effect of testosterone (Buchanan et al, 2001; Oppliger et al, 2004; Muehlenbein and Bribiescas, 2005; Alonso-Alvarez et al, 2007). This is unlikely to be the case, because oxidative damage was increased in testosterone-treated grouse, suggesting that an excess of ROS was present (Mougeot et al, 2009). Alternatively, an enhanced ROS response might not have been necessary because a sufficient testosterone-induced increase in carotenoid availability (Blas et al, 2006; McGraw et al, 2006; Alonso-Alvarez et al, 2008) fully compensated for excess ROS (but see Costantini and Møller, 2008; Martínez et al, 2009; Vinkler and Albrecht, 2010). This may be possible, given that the GO terms we used to select genes may only cover innate ROS defenses rather than dietary carotenoids. Indeed, testosterone enhanced comb redness and increased circulating carotenoid levels in one of the two study populations (Martinez-Padilla et al, 2010). However, the birds still experienced oxidative damage (Mougeot et al, 2009), suggesting that ROS could not be fully compensated for. Therefore, an enhanced mobilisation of innate ROS defences would be expected and is indeed evidenced by an in- 
crease in the birds' TAS (Mougeot et al, 2009), even when carotenoid levels were not increased (Martinez-Padilla et al, 2010). An increase in innate ROS defences, however, is not reflected in the transcriptomic data, suggesting that caecum, spleen and liver may not be the ideal tissues for investigating oxidative stress in red grouse. Nevertheless, four genes that are involved in response to oxidative damage, rather than antioxidant defence, were significantly down-regulated by testosterone in the presence of a parasite challenge, suggesting that testosterone-induced suppression of oxidative damage responses might be an alternative mechanism.

In conjunction, there is only little transcriptomic evidence for the two focal handicap models in red grouse. However, caution may be warranted because the weak transcriptomic response may potentially be an artefact of our study design and data analysis rather than evidence to accept the null hypothesis.

The experimental treatments of the underlying field study were certainly effective, given that testosterone implants caused a $2-3$ fold increase in testosterone levels, and worm counts of parasite purged and parasite challenged birds differed by a factor of six (detailed in Mougeot et al, 2009; Webster et al, 2011b). Moreover, the microarray data have been validated by quantitative PCR (qPCR), using independent RNA extracts, and showed congruence even for contrasts with low sample sizes such as TA vs. IA (Webster et al, 2011b). Nevertheless, statistical power to detect significantly differentially regulated genes might have been copromised by relatively low sample sizes in some treatment groups (3-7 birds per group). Crucially, however, some significant transcriptomic response to testosterone treatment was detected in two out of three tissues. The response was strongest in caecum tissue, but nearly absent in spleen and entirely absent in liver tissue, in spite of their endocrinological and immunological importance (Mougeot and Redpath, 2004). This inconsistency highlights that tissue choice is critical in addressing questions that involve the transcriptome. Although studying various tissues allows for identifying tissues involved in response to a treatment, restriction to only a few tissues may miss those tissues most relevant to the response of interest. While the caecum is the site of parasite infection in grouse and should therefore be the best site for investigating immune system processes (Watson et al, 1987; Shaw and Moss, 1989; Webster et al, 2011b), oxidative stress processes may have been better represented in tissues more sensitive to oxidative stress, such as brain or heart (Floyd, 1999; Bayeva and Ardehali, 2010).

Moreover, our data analysis and statistical treatment aimed to minimise the occurrence of false positives. We therefore employed moderately stringent criteria during BLAST searches, GO annotation and significance identification. As a consequence, only $30.1 \%$ of all original contigs were GO annotated and only few contigs were annotated with GO terms of interest. Nevertheless, assuming that the general mechanisms of handicap models may be underpinned by a large number of genes (Rowe and Houle, 1996), even a limited gene sample that may miss some relevant genes should be appropriate for investigating these mechanisms. We used false-discovery rate correction of $p$-values to correct for multiple significance testing and chose a stringent threshold of $5 \%$ FDR to ensure a low rate of false positives, as is common in microarray experiments (e.g. (Thompson et al, 2011; Debes et al, 2012; Matzkin, 2012)). We note that using a higher FDR threshold, or even uncorrected $p$-values rather than FDR, to identify significantly differentially regulated contigs naturally would have resulted in more identified contigs in all cases, but also in an unacceptably large number false positives for our type of study.

Apart from these caveats that are specific to our dataset, there are two general potential limitations associated with a transcriptomic approach and selection of genes through GENEONTOLOGY annotations. Firstly, the transcriptome does not necessarily predict the proteome at the final stage of gene expression. Gene transcription is only the initial step of gene expression, and various posttranscriptional regulatory mechanisms are recognised (Day and Tuite, 1998; Brockmann et al, 2007). These mechanisms confound the assumed simple relationship between mRNA and final protein, so that only as little as $20-40 \%$ of variation in protein concentration may be accounted for by the variation in mRNA levels (Brockmann et al, 2007). It is 
possible that the processes that created the previously published physiological patterns in field studies on grouse are predominantly achieved downstream of gene transcription. Nevertheless, in spite of this potential limitation, transcriptomic profiling has proven to be a useful and robust approach to characterising gene expression and identifying candidate genes (e.g. Thompson et al, 2011; Debes et al, 2012; Matzkin, 2012). Secondly, an assumption of the design is that all contigs selected for either immune system process or response to oxidative stress respond to testosterone treatment as a result of these very processes. However, given that a gene is rarely involved in a single biological process only, an entirely separate process may be responsible for a change in gene expression in response to testosterone. GENEONTOLOGY annotation reflects this complexity by allowing multiple annotation of a single gene product (The Gene Ontology Consortium, 2000). In this study, only a small proportion of significantly differentially regulated genes were annotated for a single biological process alone. Nevertheless, it is worth noting that, for example, not all immune genes with a single GO annotation for biological process responded significantly to testosterone treatment, contrary to expectations based on the ICHH.

\section{Wider implications for handicap mod- els}

In summary, our results indicate that the immunosuppressive effect of testosterone may at least partially be effected by gene-transcription changes in caecum and (to a smaller extent) spleen under parasite load. This may be consistent with the ICHH and the results of grouse field studies. Contrarily, there is no transcriptomic evidence for an increase in antioxidant activity in caecum, spleen and liver, which is inconsistent with the OSHH and field study results. However, we have shown that testosteroneinduced suppression of oxidative damage defences, rather than increase in ROS defence, might confer the oxidative stress handicap, and encourage to consider this alternative mechanism in future studies.

In spite of some weak transcriptomic support in the red grouse system, the broader literature suggests that the ICHH and OSHH are probably not always biologically realistic. The simplistic model of the original ICHH has been considerably questioned since a meta-analysis (Roberts et al, 2004) found no effect of testosterone on immunocompetence when controlled for multiple studies on the same species. Since 2004, various further studies have tested the ICHH, but positive results (e.g. Deviche and Cortez, 2005; Deviche and Parris, 2006; Cox and John-Alder, 2007; Kurtz et al, 2007; Casagrande and Groothuis, 2011; Edler et al, 2011; Gil and Culver, 2011) are contrasted with negative results (e.g. Oppliger et al, 2004; Ros et al, 2006; Alonso-Alvarez et al, 2009; Casagrande and Groothuis, 2011; Fuxjager et al, 2011; Ezenwa et al, 2012). Similarly, although the main mechanism of the OSHH is often empirically supported (e.g. Alonso-Alvarez et al, 2007, 2008; Mougeot et al, 2007, 2009, 2010a; Pérez-Rodríguez et al, 2010; Freeman-Gallant et al, 2011), environmental context may play a major role (Martinez-Padilla et al, 2010). Therefore, alternative models may be required to explain Zahavian handicaps.

In a prominently discussed alternative mechanism, the physiological stress hypothesis (Møller and Saino, 1994), the trade-off between carotenoid ornaments and body condition is not mediated by testosterone but is dependent on stress hormone levels, such as corticosterone, a glucocorticoid stress hormone involved in the mobilisation of energy sources and induction of characteristic stress behaviour (Buchanan, 2000; Sapolsky et al, 2000). Environmental stressors may cause physiological stress that becomes manifested by increased corticosterone levels (e.g. Dahl et al, 2012). Chronically elevated corticosterone levels are known to be immunosuppressive (e.g. Berger et al, 2005) and there is growing evidence that corticosterone is correlated to testosterone levels (Besedovsky et al, 1986; Evans et al, 2000; Casto et al, 2001; Buchanan et al, 2003; Owen-Ashley et al, 2004; Mateos, 2005). Testosterone and corticosterone may interact to, for example, have an immuno-enhancing effect, which has been shown in Taeniopygia guttata (zebra finch), although this incurred substantial physiological costs (Roberts et al, 2007, 2009a). Most recent evidence for a stress-mediated handicap mechanism comes 
from research on human males, whose facial characteristics correlate with cortisol (human equivalent of corticosterone) levels and immunocompetence, which itself is affected by an interaction between testosterone and cortisol (Moore et al, 2011; Rantala et al, 2012).

In red grouse, variation in corticosterone levels has been shown to explain variation between individuals in parasite load and testosterone-induced ornament enhancement (Bortolotti et al, 2009). Similarly, more recent work suggests that handicap mechanisms are context-dependent and ornaments signal condition reliably only in adverse environmental conditions, i.e. under stress (Vergara et al, 2012a,b). In our study, more immune genes and ROS response genes were significantly differentially regulated in the presence of parasites (particularly of a parasite challenge) than in absence. This effect may be partially caused by higher power caused by larger sample size in the parasite challenge group. However, even between contrasts with identical sample sizes (TA vs. IA and TN vs. IN) more genes responded under natural parasite infection than under anthelmintic treatment. This could be speculated to suggest a stress-mediated handicap mechanism in grouse as a testosterone-dependent handicap mechanism may be more pronounced in the presence of a stressor (i.e. parasites) (Bortolotti et al, 2009; Vergara et al, 2012a,b). Future work could test this more explicitly using transcriptomic profiling in response to manipulation of testosterone and corticosterone levels to disentangle the interaction between these hormones.

As an alternative perspective, Hill (2011) put forward a fundamentally different view on conditiondependent characters and signals. He defines condition as the ability to maintain vital cellular processes during environmental challenges, determined by a combination of genotypic, epigenetic and somatic states, and proposes to decouple honest signalling from fitness costs and rather link it with the functionality of cellular processes. This view is intuitively elegant, but its examination is considerably constrained by our understanding and ability to disentangle biochemical processes. Currently, the consensus view on handicaps from empirical studies is that the main mediator is probably corticosterone or an interaction of several hormones and systems (e.g. Costantini et al, 2008; Bortolotti et al, 2009; Casagrande and Groothuis, 2011; Moore et al, 2011; Ezenwa et al, 2012; Rantala et al, 2012). Driven by the recognition of physiological stress as a major factor in trade-offs (Bortolotti et al, 2009; Mougeot et al, 2010b), and given that a simple universal relationship between physiological systems and lifehistory may not exist (Versteegh et al, 2012), evolutionary ecology should focus on the individual rather than species or higher taxa, because each individual will resolve trade-offs in its own way, given genetic makeup, life-history, energetic balance and environmental context (Bortolotti et al, 2009; Martinez-Padilla et al, 2010; Versteegh et al, 2012).

This work has provided a novel perspective on investigating the assumptions of handicap models and our case study on grouse transcriptomic data points to alternative handicap models and ideas currently discussed in the literature. Much empirical research will be necessary to test the predictions of the most recent models on a genetic level and disentangle the mechanisms behind Zahavian handicaps.

\section{Supplementary material}

Tables S1+S2 Top BLAST hit descriptions for identified immune genes (S1) and ROS response genes (S2)

Tables S3+S4 Full Geneontology annotations for all significantly (FDR $<0.05)$ differentially regulated immune genes (S3) and ROS response genes (S4)

\section{Acknowledgements}

We are grateful to D. Calder and T. Helps for ac851 cess to study sites, and G. Murray-Dickson and M. Oliver for help with fieldwork and comments on 852 manuscript drafts. This work was funded by NERC grant NE/D000602/1 (SBP), a NERC advanced fellowship (FM) and a BBSRC studentship (MAW). 849

\section{.} . 


\section{References}

Alonso-Alvarez C, Bertrand S, Faivre B, Chastel O, Sorci G (2007) Testosterone and oxidative stress: The oxidation handicap hypothesis. Proc R Soc B 274(1611):819-825

Alonso-Alvarez C, Pérez-Rodríguez L, Mateo R, Chastel O, Viñuela J (2008) The oxidation handicap hypothesis and the carotenoid allocation trade-off. J Evol Biol 21(6):1789-1797

Alonso-Alvarez C, Pérez-Rodríguez L, Garcia JT, Viñuela J (2009) Testosterone-mediated tradeoffs in the old age: A new approach to the immunocompetence handicap and carotenoid-based sexual signalling. Proc R Soc B 276(1664):20932101

Andersson M (1982) Sexual selection, natural selection and quality advertisement. Biol J Linn Soc $17(4): 375-393$

Andersson M (1994) Sexual Selection. Princeton University Press, Princeton

Andersson MS, Ödeen A, Håstad O (2006) A partly coverable badge signalling avian virus resistance. Acta Zool 87:71-76

Bayeva M, Ardehali H (2010) Mitochondrial dysfunction and oxidative damage to sarcomeric proteins. Curr Hypertens Rep 12:426-432

Benjamini Y, Hochberg Y (1995) Controlling the false discovery rate: a practical and powerful approach to multiple testing. J R Statist Soc B 57:289-300

Berger S, Martin LB, Wikelski M, Romero LM, Kalko EK, Vitousek MN, Rödl T (2005) Corticosterone suppresses immune activity in territorial galapagos marine iguanas during reproduction. Horm Behav 47:419-429

Besedovsky H, Rey AD, Sorkin E, Dinarello CA (1986) Immunoregulatory feedback between interleukin-1 and glucocorticoid hormones. Science 233(4764):652-654

Blas J, Pérez-Rodríguez L, Bortolotti GR, Vinuela J, Marchant TA (2006) Testosterone increases bioavailability of carotenoids: Insights into the honesty of sexual signaling. Proc Natl Acad Sci U S A 103(49):18,633-18,637

Blount JD, Speed MP, Ruxton GD, Stephens PA (2003) Warning displays may function as honest signals of toxicity. Proc R Soc B 276(1658):871877

Boonekamp JJ, Ros AHF, Verhulst S (2008) Immune activation suppresses plasma testosterone level: A meta-analysis. Biol Lett 4(6):741-744

Bortolotti GR, Mougeot F, Martinez-Padilla J, Webster LMI, Piertney SB (2009) Physiological stress mediates the honesty of social signals. PLoS ONE 4(3):e4983

Brockmann R, Beyer A, Heinisch JJ, Wilhelm T (2007) Posttranscriptional expression regulation: What determines translation rates? PLoS Comput Biol 3(3):531-589

Buchanan KL (2000) Stress and the evolution of condition-dependent signals. Trends Ecol Evol 15(4):156-160

Buchanan KL, Evans MR, Goldsmith AR, Bryant DM, Rowe LV (2001) Testosterone influences basal metabolic rate in male house sparrows: a new cost of dominance signalling? Proc R Soc B 268:1337-1344

Buchanan KL, Evans MR, Goldsmith AR (2003) Testosterone, dominance signalling and immunosuppression in the house sparrow, passer domesticus. Behav Ecol Sociobiol 55(1):50-59

Carson SD, Chapman NM (2001) Coxsackievirus and adenovirus receptor (car) binds immunoglobulins. Biochemistry 40:14,324-14,329

Casagrande S, Groothuis TGG (2011) The interplay between gonadal steroids and immune defence in affecting a carotenoid-dependent trait. Behav Ecol Sociobiol 65(10):2007-2019

Casto JM, Nolan, Jr V, Ketterson ED (2001) Steroid hormones and immune function: Experimental studies in wild and captive dark-eyed juncos (Junco hyemalis). American Naturalist 157(4):408-420 
Conesa A, Götz S (2008) BLAST2GO: A comprehensive suite for functional analysis in plant genomics. Int J Plant Genomics 2008:619,832

Conesa A, Götz S, Garcia-Gomez JM, Terol J, Talon M, Robles M (2005) BLAst2GO: a universal tool for annotation, visualization and analysis in functional genomics research. Bioinformatics 21(18):3674-3676

Costantini D, Møller AP (2008) Carotenoids are minor antioxidants for birds. Funct Ecol 22:367-370

Costantini D, Fanfani A, Dell'Omo G (2008) Effects of corticosteroids on oxidative damage and circulating carotenoids in captive adult kestrels (Falco tinnunculus). J Comp Physiol B 178:829-835

Cox RM, John-Alder HB (2007) Increased mite parasitism as a cost of testosterone in male striped plateau lizards Sceloporus virgatus. Funct Ecol 21:327-334

Dahl E, Orizaola G, Winberg S, Laurila A (2012) Geographic variation in corticosterone response to chronic predator stress in tadpoles. J Evol Biol 25:1066-1076

Day DA, Tuite MF (1998) Post-transcriptional gene regulatory mechanisms in eukaryotes: an overview. J Endocrinol 157:361-371

Debes PV, Normandeau E, Fraser DJ, Bernatchez L, Hutchings JA (2012) Differences in transcription levels among wild, domesticated, and hybrid atlantic salmon (Salmo salar) from two environments. Mol Ecol DOI 10.1111/j.1365294X.2012.05567.x

Delahay RJ, Speakman JR, Moss R (1995) The energetic consequences of parasitism: Effects of a developing infection of Trichostrongylus tenuis (Nematoda) on red grouse (Lagopus lagopus scoticus) energy balance, body weight and condition. Parasitology 110(4):473-482

Deviche P, Cortez L (2005) Androgen control of immunocompetence in the male house finch, Carpodacus mexicanus Müller. J Exp Biol 208:12871295
Deviche P, Parris J (2006) Testosterone treatment to free-ranging male darkeyed juncos (Junco hyemalis) exacerbates hemoparasitic infection. Auk $123(2): 548-562$

Edler R, Goymann W, Schwabl I, Friedl TWP (2011) Experimentally elevated testosterone levels enhance courtship behaviour and territoriality but depress acquired immune response in red bishops Euplectes orix. Ibis 153(1):46-58

Evans MR, Goldsmith AR, Norris SRA (2000) The effects of testosterone on antibody production and plumage coloration in male house sparrows (Passer domesticus). Behav Ecol Sociobiol 47(3):156-163

Ezenwa VO, Ekernas LS, Creel S (2012) Unravelling complex associations between testosterone and parasite infection in the wild. Funct Ecol 26(1):123-133

Farah ME, Sirotkin V, Haarer B, Kakhniashvili D, Amberg DC (2011) Diverse protective roles of the actin cytoskeleton during oxidative stress. Cytoskeleton 68:340-354

Finkel T, Holbrook NJ (2000) Oxidants, oxidative stress and the biology of ageing. Nature 408:239247

Floyd RA (1999) Antioxidants, oxidative stress, and 1006 degenerative neurological disorders. PSEMBM ${ }_{1007}$ 222:236-245

Folstad I, Karter AJ (1992) Parasites, bright males, 1009 and the immunocompetence handicap. Am Nat 1010 139(3):603-622

Freeman-Gallant CR, Amidon J, Berdy B, Wein S, 1012 Taff CC, Haussmann MF (2011) Oxidative dam- ${ }_{1013}$ age to dna related to survivorship and carotenoid- 1014 based sexual ornamentation in the common yel- 1015 lowthroat. Biol Lett 7(3):429-432

Fuxjager MJ, Foufopoulos J, Diaz-Uriarte R, Mar- ${ }_{1017}$ ler CA (2011) Functionally opposing effects of 1018 testosterone on two different types of parasite: 1019 implications for the immunocompetence handi- 1020 cap hypothesis. Funct Ecol 25(1):132-138 1004 mo (1) 
Gil D, Culver R (2011) Male ornament size in a passerine predicts the inhibitory effect of testosterone on macrophage phagocytosis. Funct Ecol $25(6): 1278-1283$

Grafen A (1990) Biological signals as handicaps. J Theor Biol 144:517-546

Gray CP, Franco AV, Arosio P, Hersey P (2001) Immunosuppressive effects of melanoma-derived heavy-chain ferritin are dependent on stimulation of il-10 production. Int J Cancer 92:843-850

Hamilton W, Zuk M (1982) Heritable true fittness and bright birds: a role for parasites? Science 218:384-387

Hasselquist D, Marsh JA, Sherman PW, Wingfield JC (1999) Is avian humoral immunocompetence suppressed by testosterone? Behav Ecol Sociobiol 45:167-175

Hill GE (2011) Condition-dependent traits as signals of the functionality of vital cellular processes. Ecol Lett 14:625-634

Hill GE, Farmer KL (2005) Carotenoid-based plumage coloration predicts resistance to a novel parasite in the house finch. Naturwissenschaften $92: 30-34$

Hudson PJ, Dobson AP, Newborn D (1992) Do parasites make prey vulnerable to predation? Red grouse and parasites. J Anim Ecol 61(3):681-692

Kurtz J (2007) The correlation between immunocompetence and an ornament trait changes over lifetime in Panorpa vulgaris scorpionflies. Zoology $110(5): 336-343$

Kurtz J, Kalbe M, Langefors A, Mayer I, Milinski M, Hasselquist D (2007) An experimental test of the immunocompetence handicap hypothesis in a teleost fish: 11-ketotestosterone suppresses innate immunity in three-spined sticklebacks. Am Nat 170(4):509-519

Martinez-Padilla J, Mougeot F, Pérez-Rodríguez L, Bortolotti GR (2007) Nematode parasites reduce carotenoid-based signalling in male red grouse. Biol Lett 3(2):161-164
Martinez-Padilla J, Mougeot F, Webster LMI, 1063 Pérez-Rodríguez L, Piertney SB (2010) Testing ${ }_{1064}$ the interactive effects of testosterone and para- 1065 sites on carotenoid-based ornamentation in a wild $\quad{ }_{1066}$ bird. J Evol Biol 23(5):902-913 1067

Martínez A, Rodríguez-Gironés MA, Barbosa A ${ }_{1068}$ (2009) Can bird carotenoids play an antioxi- 1069 dant role oxidizing other substances? Ardeola ${ }_{1070}$ $56(2): 287-294$

Mateos C (2005) The subordination stress paradigm 1072 and the relation between testosterone and corti- ${ }_{1073}$ costerone in male ring-necked pheasants. Anim 1074 Behav 69:249-255

Matzkin LM (2012) Population transcriptomics of 1076 cactus host shifts in Drosophila mojavensis. Mol ${ }_{1077}$ Ecol DOI 10.1111/j.1365-294X.2012.05549.x 1078

Maynard Smith J (1974) The theory of games and 1079 the evolution of animal conflicts. J Theor Biol 1080 $47: 209-221$

McGraw KJ, Correa SM, Adkins-Regan E (2006) ${ }_{1082}$ Testosterone upregulates lipoprotein status to ${ }_{1083}$ control sexual attractiveness in a colorful song- ${ }_{1084}$ bird. Behav Ecol Sociobiol 60:117-122

Møller AP, Saino N (1994) Parasites, immunology 1086 of hosts, and host sexual selection. J Parasitol ${ }_{1087}$ 80(6):850-858

Møller AP, Dufva R, Erritzoe J (1998) Host immune ${ }_{1089}$ function and sexual selection in birds. J Evol Biol 1090 11:703-719

Møller AP, Christe P, Lux E (1999) Parasitism, host 1092 immune function, and sexual selection. Q Rev ${ }_{1093}$ Biol 74:3-20

Moore FR, Cornwell RE, Law Smith MJ, Al Du- ${ }_{1095}$ jaili EAS, Sharp M, Perrett DI (2011) Evidence 1096 for the stress-linked immunocompetence handi- ${ }_{1097}$ cap hypothesis in human male faces. Proc R Soc 1098 B 278(1706):774-780

Moore SL, Wilson K (2002) Parasites as a viability ${ }_{1100}$ cost of sexual selection in natural populations of ${ }_{1101}$ mammals. Science 297:2015-2018

\section{.

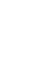

-

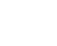


Mougeot F (2008) Ornamental comb colour predicts t-cell-mediated immunity in male red grouse Lagopus lagopus scoticus. Naturwissenschaften 95(2):125-132

Mougeot F, Redpath SM (2004) Sexual ornamentation relates to immune function in male red grouse Lagopus lagopus scoticus. J Avian Biol $35(5): 425-433$

Mougeot F, Irvine JR, Seivwright L, Redpath SM, Piertney S (2004) Testosterone, immunocompetence, and honest sexual signaling in male red grouse. Behav Ecol 15(6):930-937

Mougeot F, Redpath SM, Piertney SB (2006) Elevated spring testosterone increases parasite intensity in male red grouse. Behav Ecol 17(1):117-125

Mougeot F, Pérez-Rodríguez L, Martínez-Padilla J, Leckie F, Redpath SM (2007) Parasites, testosterone and honest carotenoid-based signalling of health. Funct Ecol 21:886-898

Mougeot F, Martínez-Padilla J, Webster LMI, Blount JD, Pérez-Rodríguez L, Piertney SB (2009) Honest sexual signalling mediated by parasite and testosterone effects on oxidative balance. Proc R Soc B 276(1659):1093-1100

Mougeot F, Martinez-Padilla J, Blount JD, PérezRodríguez L, Webster LMI, Piertney SB (2010a) Oxidative stress and the effect of parasites on a carotenoid-based ornament. J Exp Biol 213(3):400-407

Mougeot F, Martinez-Padilla J, Bortolotti GR, Webster LMI, Piertney SB (2010b) Physiological stress links parasites to carotenoid-based colour signals. J Evol Biol 23(3):643-650

Muehlenbein MP, Bribiescas RG Testosterone-mediated immune functions and male life histories. Am J Hum Biol 17:527-558

Myhre S, Tveit H, Mollestad T, Lægreid A (2006) Additional gene ontology structure for improved biological reasoning. Bioinformatics 22(16):20202027

Olson VA, Owens IP (1998) Costly sexual signals: are carotenoids rare, risky or required? Trends Ecol Evol 13(12):510-514
Oppliger A, Giorgi MS, Conelli A, Nembrini ${ }_{1146}$ M, John-Alder HB (2004) Effect of testos- ${ }_{1147}$ terone on immunocompetence, parasite load, and ${ }_{1148}$ metabolism in the common wall lizard (Podarcis 1149 muralis). Can J Zool 82(11):1713-1719

Ottová E, Simková A, Jurajda P, Dávidová M, Ondracková M, Pecínková M, Gelnar M (2005) Sex- ${ }_{1152}$ ual ornamentation and parasite infection in males ${ }_{1153}$ of common bream (Abramis brama): a reflection $\quad{ }_{1154}$ of immunocompetence status or simple cost of re- $\quad 1155$ production? Evol Ecol Res 7:581-593

Owen-Ashley NT, Hasselquist D, Wingfield JC ${ }_{1157}$ (2004) Androgens and the immunocompetence ${ }_{1158}$ handicap hypothesis: unraveling direct and in- 1159 direct pathways of immunosuppression in song 1160 sparrows. Am Nat 164(4):490-505

Pemberton JM, Beraldi D, Craig BH, Hopkins ${ }_{1162}$ J (2011) Digital gene expression analysis of ${ }_{1163}$ gastrointestinal helminth resistance in scottish 1164 blackface lambs. Mol Ecol 20:910-919

Peters A, Denk AG, Delhey K, Kempenaers B ${ }_{1160}$ (2004) Carotenoid-based bill colour as an indi- ${ }^{1167}$ cator of immunocompetence and sperm perfor- 1168 mance in male mallards. J Evol Biol 17:1111-1120 1169

Pérez-Rodríguez L, Mougeot F, Alonso-Alvarez C ${ }_{1170}$ (2010) Carotenoid-based coloration predicts re- ${ }_{1171}$ sistance to oxidative damage during immune 1172 challenge. J Exp Biol 213:1685-1690

Rantala MJ, Moore FR, Skrinda I, Krama T, Kivle- $\quad{ }_{1174}$ niece I, Kecko S, Krams I (2012) Evidence for ${ }_{1175}$ the stress-linked immunocompetence handicap 1176 hypothesis in humans. Nat Commun 3:694 1177

Roberts ML, Buchanan KL, Evans MR (2004) Test- ${ }_{1178}$ ing the immunocompetence handicap hypothesis: 1179 a review of the evidence. Anim Behav 68:227-239 1180

Roberts ML, Buchanan KL, Hasselquist D, Evans ${ }_{1181}$ MR (2007) Effects of testosterone and corticos- ${ }_{1182}$ terone on immunocompetence in the zebra finch. ${ }_{1183}$ Horm Behav 51(1):126-134

Roberts ML, Buchanan KL, Evans MR, Marin RH, 1185 Satterlee DG (2009a) The effects of testosterone ${ }_{1186}$ 
on immune function in quail selected for divergent plasma corticosterone response. J Exp Biol $212(19): 3125-3131$

Roberts ML, Ras E, Peters A (2009b) Testosterone increases uv reflectance of sexually selected crown plumage in male blue tits. Behav Ecol 20(3):535541

Ros AFH, Bouton N, Santos RS, Oliveira RF (2006) Alternative male reproductive tactics and the immunocompetence handicap in the azorean rockpool blenny, Parablennius parvicornis. Proc R Soc B 273:901-909

Rowe L, Houle D (1996) The lek paradox and the capture of genetic variance by condition dependent traits. Proc R Soc B 263:1415-1421

Sapolsky RM, Romero LM, Munck AU (2000) How do glucocorticoids influence stress responses? integrating permissive, suppressive, stimulatory, and preparative actions. Endocr Rev 21(1):55-89

Schmid-Hempel P (2003) Variation in immune defence as a question of evolutionary ecology. Proc R Soc B 270:357-366

Seivwright LJ, Redpath SM, Mougeot F, Leckie F, Hudson PJ (2005) Interactions between intrinsic and extrinsic mechanisms in a cyclic species: testosterone increases parasite infection in red grouse. Proc R Soc B 272(1578):2299-2304

Shaw JL, Moss R (1989) Factors affecting the establishment of the caecal threadworm Trichostrongylus tenuis in red grouse (Lagopus lagopus scoticus). Parasitology 99(2):259-264

Strimmer K (2008) A unified approach to false discovery rate estimation. BMC Bioinformatics 2008 9:303

The Gene Ontology Consortium (2000) Gene Ontology: tool for the unification of biology. Nat Genet 25:25-29

Thompson AW, Huang K, Saito MA, Chisholm SW (2011) Transcriptome response of high- and lowlight-adapted Prochlorococcus strains to changing iron availability. ISME J 5:1580-1594
Vergara P, Martinez-Padilla J, Mougeot F, Leckie ${ }_{1228}$ F, Redpath SM (2012a) Environmental hetero- ${ }_{1229}$ geneity influences the reliability of secondary sex- 1230 ual traits as condition indicators. J Evol Biol ${ }_{1231}$ 25(1):20-28

Vergara P, Mougeot F, Martinez-Padilla J, Leckie ${ }_{1233}$ F, Redpath SM (2012b) The condition depen- ${ }^{1234}$ dence of a secondary sexual trait is stronger under ${ }_{1235}$ high parasite infection level. Behavioral Ecology 1236 23(3):502-511

Versteegh MA, Schwabl I, Jaquier S, Tieleman ${ }^{1238}$ BI (2012) Do immunological, endocrine and ${ }_{1239}$ metabolic traits fall on a single pace-of-life axis? 1240 covariation and constraints among physiologi- ${ }^{1241}$ cal systems. J Evol Biol DOI 10.1111/j.1420- ${ }_{1242}$ 9101.2012.02574.x

Vinkler M, Albrecht T (2010) Carotenoid ${ }^{1244}$ maintenance handicap and the physiology 1245 of carotenoid-based signalisation of health. 1246 Naturwissenschaften 97(1):19-28 ${ }^{1247}$

von Schantz T, Bensch S, Grahna M, Hasselquist D, ${ }_{1248}$ Wittzell H (1999) Good genes, oxidative stress 1249 and condition-dependent sexual signals. Proc R 1250 Soc B 266:1-12

Watson H, Lee DL, Hudson PJ (1987) The effect ${ }_{1252}$ of Trichostrongylus tenuis on the caecal mucosa ${ }_{1253}$ of young, old and anthelmintic-treated wild red ${ }_{1254}$ grouse, Lagopus lagopus scoticus. Parasitology 1255 94(2):405-411

Webster LMI, Mello LV, Mougeot F, Martinez- ${ }^{1257}$ Padilla J, Paterson S, Piertney SB (2011a) Iden- ${ }_{1258}$ tification of genes responding to nematode infec- 1259 tion in red grouse. Mol Ecol Res 11(2):305-313 1260

Webster LMI, Paterson S, Mougeot F, Martinez- ${ }^{1261}$ Padilla J, Piertney SB (2011b) Transcriptomic ${ }_{1262}$ response of red grouse to gastro-intestinal nema- ${ }^{1263}$ tode parasites and testosterone: Implications for ${ }^{1264}$ population dynamics. Mol Ecol 20(5):920-931 1265

Wilson GR (1983) The prevalence of caecal thread- ${ }^{1266}$ worms (Trichostrongylus tenuis) in red grouse ${ }^{1267}$ (Lagopus lagopus scoticus). Oecologia 58:265-268 1268

Zahavi A (1975) Mate selection - a selection for a ${ }_{1269}$ handicap. J Theor Biol 53:205-214 
Table 1: Gene product identification results after hierarchical BLAST interrogation of 5,925 contigs against three databases (SWISSPROT, then CHICKEN GENBANK PROTEIN, then ZEBRAFINCH GENBANK PROTEIn) followed by GEnEOntology (GO) annotation. The total number of hits are also given as the $\underline{\text { percentage of the total dataset }(5,925 \text { contigs }) \text {. }}$

SWISSPROT CHICKEN ZEBrafinch Total $\%$

\begin{tabular}{|c|c|c|c|c|c|}
\hline \multicolumn{6}{|l|}{ Protein database hits } \\
\hline BLAST hits & 1,801 & 60 & 3 & 1,864 & 31.5 \\
\hline GO hits & 1,746 & 33 & 2 & 1,781 & 30.1 \\
\hline \multicolumn{6}{|l|}{ GO term hits } \\
\hline GO:0002376 immune system process & 280 & 2 & 0 & 282 & 4.8 \\
\hline \multicolumn{6}{|l|}{ GO:0006979 response to oxidative stress } \\
\hline + GO:0016209 antioxidant activity & 65 & 0 & 0 & 65 & 1.1 \\
\hline
\end{tabular}


Table 2: Characterisation of significantly $(q<0.05)$ differentially regulated contigs in response to testosterone. Each row represents one contig and combines significant fold changes for three parasite treatment groups (TA vs. IA, TN vs. IN and TP vs. IP) per tissue. The gene product description is given alongside the number of GO annotations in cellular component $(\mathrm{C})$, molecular function $(\mathrm{F})$ and biological process $(\mathrm{P})$ ontologies, and database accessions for the protein swissPROT hit and the original contig sequence (GenBank EST).

\begin{tabular}{|c|c|c|c|c|c|c|c|c|c|}
\hline \multirow[b]{2}{*}{ Tissue } & \multicolumn{3}{|c|}{ Fold change } & \multirow[b]{2}{*}{ Gene product (BLAST description) } & \multicolumn{3}{|c|}{ GO terms } & \multicolumn{2}{|c|}{ Accessions } \\
\hline & TA & $\mathrm{TN}$ & $\mathrm{TP}$ & & $\mathrm{C}$ & $\mathrm{F}$ & $\mathrm{P}$ & Protein & Contig \\
\hline \multicolumn{10}{|c|}{ GO:0002376 immune system process } \\
\hline Caecum & - & - & -1.79 & Ubiquitin-40S ribosomal protein $\mathrm{S} 27 \mathrm{a}$ & 5 & 2 & 35 & P79781 & GW704812 \\
\hline Caecum & - & - & -1.63 & Ig lambda chain V-1 region & 3 & 1 & 2 & P04210 & GW704581 \\
\hline Caecum & - & -1.80 & -1.40 & Ig lambda chain $\mathrm{V}-1$ region & 2 & 2 & 2 & P04210 & GW700881 \\
\hline Caecum & - & - & -1.16 & Caspase recruitment domain-containing protein 11 & 5 & 4 & 22 & Q9BXL7 & GW704745 \\
\hline Caecum & - & - & -1.14 & HLA class II histocompatibility antigen gamma chain & 5 & 2 & 12 & P04233 & GW704842 \\
\hline Caecum & - & - & -1.02 & T-cell surface glycoprotein CD3 delta chain & 1 & 2 & 6 & Q764N2 & GW705191 \\
\hline Caecum & - & - & -0.90 & Myosin-11 & 24 & 9 & 41 & $\mathrm{P} 10587$ & GW706306 \\
\hline Caecum & - & - & -0.83 & Dual specificity protein phosphatase 1 & 5 & 4 & 33 & P28562 & GW706824 \\
\hline Caecum & - & - & -0.82 & Myosin-11 & 24 & 9 & 41 & P10587 & GW703178 \\
\hline Caecum & - & - & -0.77 & Complement factor I & 5 & 1 & 4 & Q61129 & GW703417 \\
\hline Caecum & - & - & -0.77 & Kininogen-1 & 2 & 2 & 12 & P01044 & GW704416 \\
\hline Caecum & - & -1.16 & -0.69 & Gelsolin & 12 & 6 & 27 & O93510 & GW704663 \\
\hline Caecum & - & - & -0.65 & Ras-related C3 botulinum toxin substrate 2 & 16 & 15 & 62 & P15153 & GW705819 \\
\hline Caecum & - & - & -0.64 & Immunoglobulin $\mathrm{J}$ chain & 2 & 1 & 1 & P01592 & GW699715 \\
\hline Caecum & - & - & -0.59 & YTH domain family protein 2 & 0 & 0 & 1 & Q4R5D9 & GW705307 \\
\hline Caecum & - & - & -0.58 & Lymphocyte antigen $6 \mathrm{E}$ & 3 & 0 & 3 & Q90986 & GW704464 \\
\hline Caecum & - & - & -0.40 & $72 \mathrm{kDa}$ type IV collagenase & 8 & 8 & 46 & Q90611 & GW705867 \\
\hline Caecum & - & - & 0.41 & Coxsackievirus and adenovirus receptor & 4 & 1 & 8 & P78310 & GW706459 \\
\hline Caecum & - & - & 0.48 & Coxsackievirus and adenovirus receptor homolog & 7 & 2 & 11 & Q9R066 & GW700528 \\
\hline Caecum & - & - & 0.56 & Ferritin heavy chain & 3 & 3 & 12 & P08267 & GW700124 \\
\hline Caecum & - & -1.30 & - & Myosin-9 & 24 & 9 & 41 & P14105 & GW704927 \\
\hline Caecum & - & -0.72 & - & Coronin-1C & 6 & 4 & 10 & Q9ULV4 & GW705584 \\
\hline Spleen & - & -1.42 & - & Elongator complex protein 1 & 4 & 6 & 5 & O95163 & GW701060 \\
\hline Spleen & - & -0.94 & - & Plastin-2 & 10 & 5 & 13 & P13796 & GW702767 \\
\hline Spleen & - & 1.01 & - & Ferritin heavy chain & 3 & 3 & 12 & P08267 & GW699682 \\
\hline \multicolumn{10}{|c|}{ + GO:0016209 antioxidant activity } \\
\hline Caecum & - & - & -0.83 & Dual specificity protein phosphatase 1 & 5 & 4 & 33 & P28562 & GW706824 \\
\hline Caecum & - & - & -0.76 & Serine/threonine-protein kinase Sgk1 & 7 & 8 & 25 & Q6U1I9 & GW705373 \\
\hline Caecum & - & - & -0.61 & Bile salt export pump & 7 & 7 & 20 & O95342 & GW701767 \\
\hline Caecum & - & - & -0.40 & $72 \mathrm{kDa}$ type IV collagenase & 8 & 8 & 46 & Q90611 & GW705867 \\
\hline Caecum & - & 1.41 & - & Actin & 6 & 2 & 15 & P60009 & GW699904 \\
\hline
\end{tabular}


Table 3: Numbers of significantly $(q<0.05)$ differentially regulated contigs in response to testosterone (increased testosterone levels $\mathrm{T}$ compared to natural levels I) in three tissues, three parasite treatment groups (anthelmintic A, natural chronic infection $\mathrm{N}$ and parasite challenge $\mathrm{P}$ ) and selected Go terms.

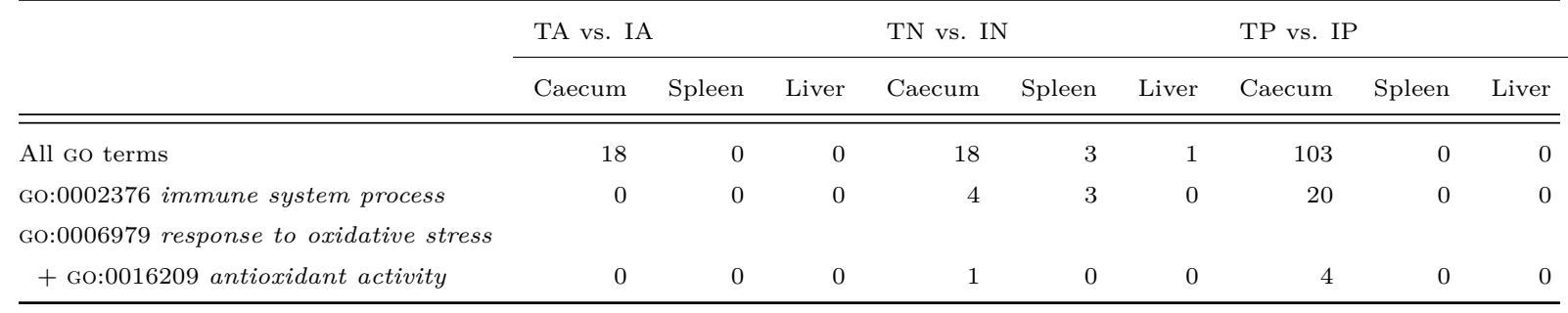


Anthelmintic

(TA vs. IA)
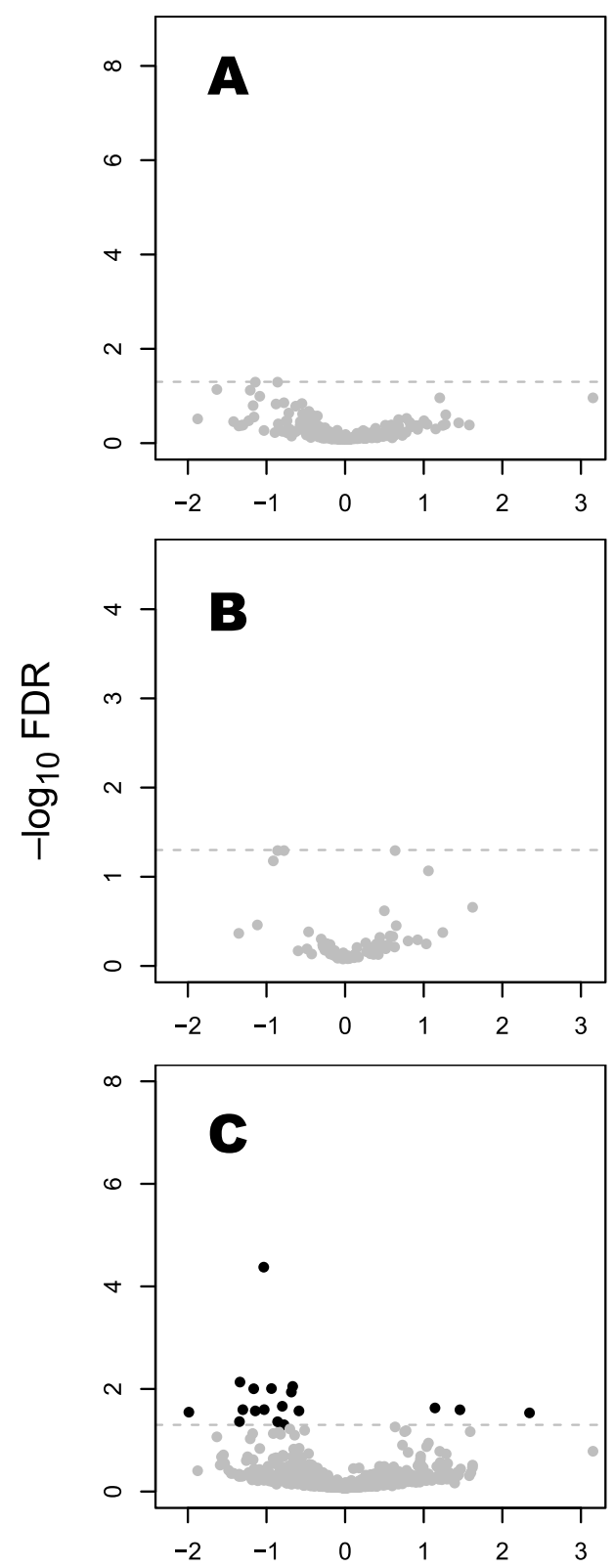

Natural infection

(TN vs. IN)
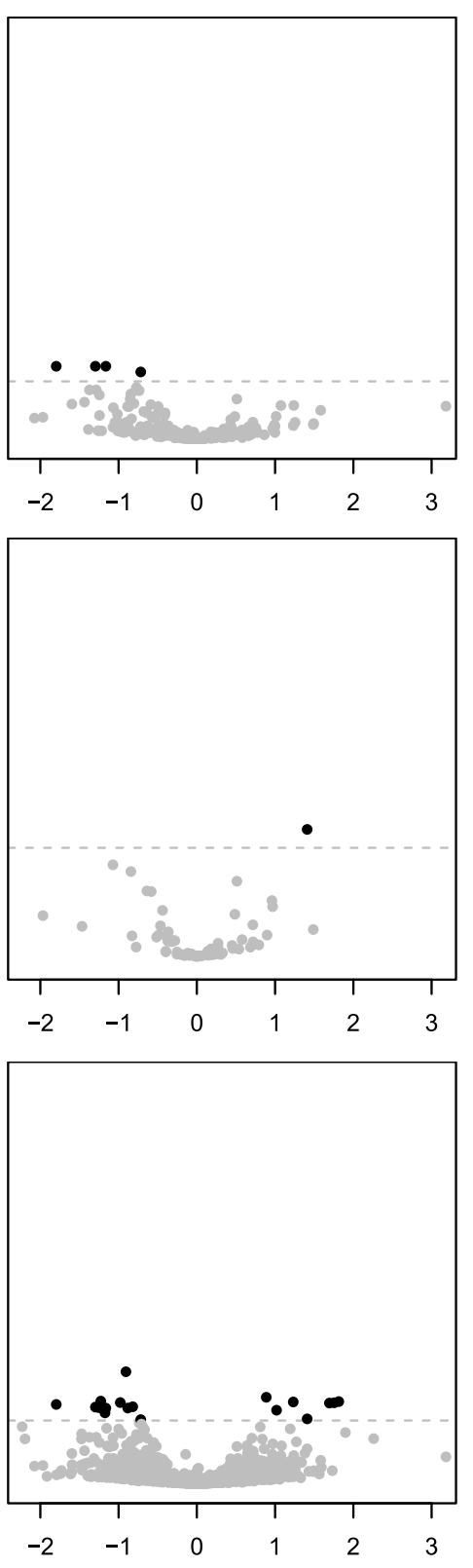

Parasite challenge

(TP vs. IP)
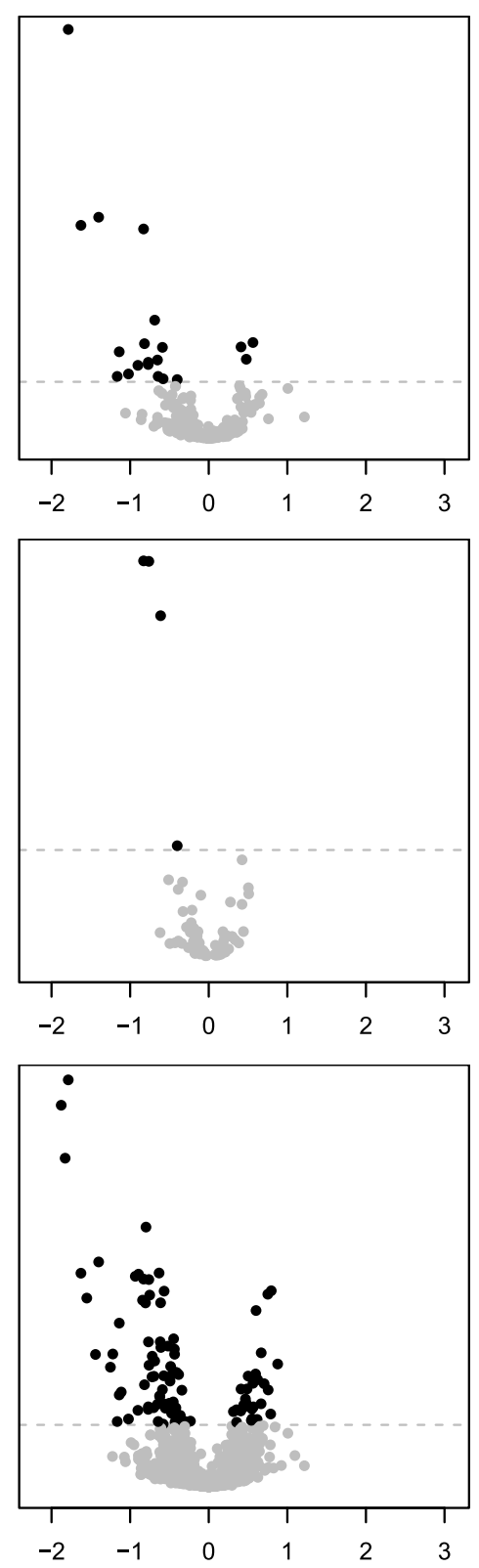

$\log _{2}$ fold change

Fig. 1: Transcriptomic response of caecum to increased (T) contrasted with natural testosterone levels (I) in three parasite treatment groups (anthelmintic A, natural chronic infection $\mathrm{N}$ and parasite challenge P). Volcano plots relate biological significance (fold change) to statistical significance (false-discoveryrate adjusted $q$-value) of gene transcription changes. Each dot represents one contig, GO-annotated with GO:0002376 immune system process (row A), GO:0006979 response to oxidative stress or GO:0016209 antioxidant activity (row B), or any GO term (row C). Black dots are statistically significant $(q<0.05$; dashed grey line indicates cut-off). 


\section{GO level 2}

TA vs. IA

biological regulation cellular process

multicellular organismal process

metabolic process

response to stimulus

developmental process

signaling

locomotion

death

cell proliferation

reproduction

biological adhesion

growth

cellular component organization localization

TN vs. IN

cellular process

biological regulation

cellular component organization

response to stimulus

metabolic process

developmental process

multicellular organismal process

cellular component biogenesis

locomotion

localization

signaling

death

immune system process

TP vs. IP

cellular process

biological regulation

metabolic process

response to stimulus

multicellular organismal process

developmental process

localization

cellular component organization

signaling

cell proliferation

cellular component biogenesis

death

reproduction

growth

multi-organism process

immune system process

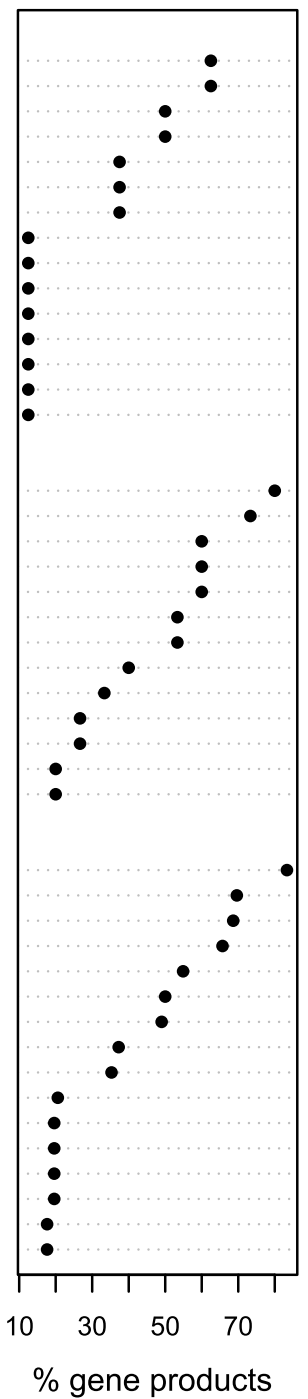

TA vs. IA

regulation of biological process biosynthetic process

small molecule metabolic process

cellular metabolic process

primary metabolic process

multicellular organismal development

regulation of biological quality

catabolic process

nitrogen compound metabolic process

cellular response to stimulus

anatomical structure development

macromolecule metabolic process

TN vs. IN

regulation of biological process primary metabolic process macromolecule metabolic process cellular metabolic process

multicellular organismal development response to chemical stimulus regulation of biological quality cellular developmental process cellular component assembly anatomical structure development response to stress

biosynthetic process

small molecule metabolic process

organelle organization

cell projection organization

TP vs. IP

primary metabolic process

cellular metabolic process

regulation of biological process

nitrogen compound metabolic process

macromolecule metabolic process

multicellular organismal development

cellular response to stimulus

establishment of localization anatomical structure development response to stress

small molecule metabolic process regulation of biological quality response to chemical stimulus

catabolic process

biosynthetic process

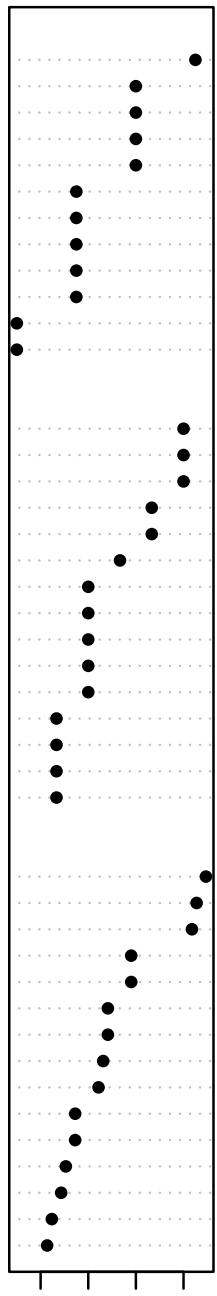

$30 \quad 50$

$\%$ gene products

Fig. 2: Illustration of functional broadness of all GO-annotated contigs significantly differentially regulated in response to testosterone. Most frequent level-2 and level-3 GO annotations in biological process ontology are listed with percentages of annotated gene products for each GO annotation in each treatment contrast (TA vs. IA, TN vs. IN and TP vs. IP). 